\title{
IN-VITRO AND IN-VIVO CHARACTERIZATION OF MOUTH DISSOLVING TABLET: AN UPDATED REVIEW
}

\author{
*Kumar Pankaj ${ }^{1}$, Kaur Parminder ${ }^{1}$, Kaur Poonamjeet ${ }^{1}$, Piplani Mona ${ }^{2}$ \\ ${ }^{1}$ Sachdeva college of Pharmacy, Gharuan (Kharar), India \\ ${ }^{2}$ Institute of Pharmaceutical Sciences Kurukshetra University, Kurukshetra, India
}

*Corresponding Author's E-mail: Pankaj_1686@yahoo.co.in

\begin{abstract}
Mouth dissolving tablets (MDTs) has extended much attention as a preferred alternative to conventional oral dosage form. It provides an advantage particularly for pediatric and geriatric populations who have difficulty in swallowing conventional tablets and capsules. MDTs have the unique property of rapidly disintegrating and/ or dissolving or releasing the drug as soon as they come in contact with saliva, thus obviating the requirement of water during administration. The current review describes the ideal characteristics, significance, limitations and mainly lays emphasis on the in-vitro and in-vivo characterization of MDT.
\end{abstract}

Keywords: Mouth dissolving tablets, disintegration, in-vivo and in-vitro evaluation, dysphagia.

\section{INTRODUCTION}

MDTs are also called as orally disintegrating tablets, orodispersible tablets, fast dissolving tablets, rapid dissolving tablets, rapid disintegrating tablets, porous tablets and rapi melts. ${ }^{1}$ Oral route is most preferred route by medical practitioners and manufacturer due to highest acceptability of patients. $^{2}$ Oral routes of drug administration have world wide acceptance up to 50-60\% of total dosage forms. ${ }^{3}$ However, tablets are most favorite and popular among the currently used dosage forms and efficacy of these dosage forms have been clinically evaluated because of its convenience in terms of self medication, compactness, ease in manufacturing, pain avoidance, and versatility. ${ }^{4-7}$ It has been reported that Dysphagia (difficulty in swallowing) is common among all age groups and more specific with pediatric, geriatric population along with institutionalized patients and patients with nausea, vomiting, and motion sickness complications. ${ }^{8,9}$ To avert the problems associated with conventional dosage forms, MDTs have been developed, which combine hardness, dosage uniformity, stability and other parameters, with extremely easy administration, since no water is required for swallowing the tablets and they are thus suitable for geriatric, pediatric and travelling patients. ${ }^{10-13}$ For these reason, scientists have developed the innovative concept of Mouth Dissolving Drug Delivery System (MDDDS) emerged from the desire to provide patient with more conventional means of taking their medications. MDDDS have started gaining popularity and acceptance as new drug delivery systems. These tablets disintegrate into smaller granules or melts in the mouth from a hard solid to a gel like structure, allowing easy swallowing by patients. The disintegration time for good MDTs varies from several seconds to about a minute. ${ }^{14}$ United States Food and Drug Administration(US FDA) defined MDTs as "A solid dosage form containing medicinal substance or active pharmaceutical ingredients(API) which disintegrates rapidly usually within seconds when placed upon the tongue ${ }^{15}$.
The basic approach in development of MDT is the use of superdisintegrants like crospovidone, croscarmellose sodium (Ac-Di-Sol), sodium starch glycolate etc. as synthetic superdisintegrants in the formulation of MDTs, which provide instantaneous disintegration of tablet after keeping on tongue, their by release the drug in saliva. ${ }^{16}$ The proper selection of disintegrant or superdisintegrant and its consistency of performance are of critical importance in formulation development of such tablets. ${ }^{17}$ Various technologies used for manufacturing MDTs include freeze drying, spray drying, tablet molding, sublimation, direct compression, sugar-based excipients, and disintegrant addition. ${ }^{18}$ Recent market studies indicate that ore than half of the patient population prefer MDTs to other dosage forms such as regular tablets or liquids $(>80 \%) .{ }^{19]}$ Furthermore, market size and popularity of these dosage forms will surely expand in future. This article is emphasized on the in-vivo and in-vitro evaluation of MDTs along with ideal properties, significance, and limitations of MDTs.

\section{IDEAL CHARACTERISTICS OF MDTS}

MDTs have several ideal characteristics to distinguish them from the more traditional dosage forms. ${ }^{[20-28]}$ These tablets should:

$>$ Not require water or other liquid to swallow.

$>$ Give good mouth feel.

$>$ Easily Dissolve/Disperse/Disintegrate in saliva within few seconds.

$>$ Have a satisfactory taste masking properties.

$>$ Cost effectiveness.

$>$ Show signs of low sensitivity to environmental conditions like temperature, humidity etc.

$>$ Be harder and less friable.

$>$ Leave minimal or no residue in mouth after administration.

$>$ Allow the manufacture of tablet using conventional processing and packaging equipments. 
$>$ Allow high drug loading.

$>$ Be portable without fragility concerns.

\section{SIGNIFICANCE OF MDTS}

MDTs offer all advantages of solid dosage forms and liquid dosage forms along with special advantages ${ }^{1,29-42}$ which include:

Improved compliance/added convenience.

$>$ Achieve increased bioavailability/rapid absorption through pregastric absorption of drugs from mouth, pharynx and oesophagus as saliva passes down.

Rapid drug therapy intervention.

$>$ Good mouth feel property helps to change the perception of medication as "bitter pill" particularly in pediatric patients.

Risk of chocking or suffocation during oral administration is avoided, thus providing improved safety.

No water needed.

$>$ No chewing needed.

Improved stability.

No special set up required for the industry.

Rapid onset of action.

$>$ Lower doses.

D New business opportunities like product differentiation, line extension, and life-cycle management, exclusivity of product promotion and patent-life extension.

Accurate dosing.

Small packaging size.

\section{LIMITATIONS OF MDTS}

The factors responsible for limiting their use vary from formulation till the effect of drug in the body. ${ }^{10,43-45}$ These are:

> MDTs usually have inadequate mechanical strength. Hence, vigilant handling is required during formulation process.

$>$ The tablets may leave disagreeable taste and/or grittiness in mouth if not formulated appropriately.

$>$ Drugs with larger doses are difficult to formulate into MDTs e.g. Rifampin (600mg), ethambutol (1000mg) etc.

$>$ Taste masking is required.

$>$ Proteinaceous drugs should be avoided, if coadministration of enzyme inhibitors such as aprotinin, bestatin, puromicin and bile salts are required for the inhibition of proteolytic enzymes present in saliva.

$>$ Patients who concomitantly take anticholinergic medication may not be the best candidates for MDTs and patients like Sjogren's syndrome or dryness of the mouth due to decrease saliva production may not be good candidates for these tablet formulation.

\section{IN-VITRO CHARACTERIZATION OF MDTS}

Enormous work has been done in this field, wherein some of the researchers have developed their own methods of evaluation. In the recent past, several new advanced technologies have been introduced for the formulation of MDTs. To ensure drug release from MDTs, the dosage form requires thorough and meticulous evaluation for optimum performance, which can be assessed indirectly by in-vitro technologies.

\section{Evaluation of tablets}

Evaluation parameters of tablets mentioned in the pharmacopoeias used to be assessed, along with some special tests are discussed. ${ }^{33}$ These include: organoleptic evaluation, weight variation, thickness, hardness, friability, wetting time, water absorption ratio, in-vitro disintegration test, drug content uniformity, swelling index, in-vitro drug release studies and moisture uptake studies.

\section{Organoleptic properties}

This is essential step in case of most oral formulation due to more residence time in the oral cavity. General appearance of a tablet, its visual identity and over all "elegance" is essential for consumer acceptance. Include in are tablet's size, shape, colour, presence or absence of an odour, taste, surface texture, physical flaws and consistency and legibility of any identifying marking. $24,34,48$ In-vitro methods of utilizing taste sensors, specially designed apparatus and drug release by modified pharmacopoeial methods are being used for this purpose. Experiments using electronic tongue measurements are reported to distinguish between the sweetness levels in taste-masking formulation.

\section{Weight variation}

Twenty tablets are selected at a random from each formulation and average weight is determined. Then individual tablets are weighed using digital electronic balance and the individual weight is compared with the average weight. The mean \pm SD (standard deviation) values are calculated. ${ }^{49}$ The weight variation test would be a satisfactory method of assessing the drug content uniformity.

\section{Thickness}

Tablet thickness is an important characteristic in reproducing appearance and also in counting. Three tablets are taken randomly from each formulation and their thickness is measured with Vernier caliper. The mean \pm SD values are calculated. ${ }^{34,49}$

\section{Hardness}

Hardness of the tablet is defined as the force applied across the diameter of the tablet in order to break the tablet. Hardness of the tablets is measured using Pfizer type hardness tester. Three tablets are selected from each formulation randomly and their hardness is measured. The resistance of the tablet to abrasion, chipping or breakage under conditions of storage and handling before usage depends on its hardness. The mean \pm SD of hardness values are calculated. It is expressed in $\mathrm{Kg} /$ pound..$^{50,51}$

\section{Friability}

Friability of the tablets is determined using Roche friabilator. This device subjects a number of tablets to the combined effect of abrasions and shock in a plastic chamber revolving at $25 \mathrm{rpm}$ and dropping the tablets at 
distance of six inches with each revolution. Preweighed sample of tablets is placed in the fribilator and are subjected to 100 revolutions. ${ }^{52,53}$ Tablets are then dedusted and reweighed and percentage of weight loss is calculated by the formula:

$$
\text { Friability }=\frac{\text { Initial weight }- \text { Final weight }}{\text { Initial weight }} \times 100
$$

\section{Wetting time}

Wetting time of dosage form is related to the contact angle. It needs to be assessed to give an insight into the disintegration properties of the tablets; a lower wetting time implies a quicker disintegration of the tablet. For this purpose, a piece of tissue paper folded twice is placed in a small petridish (i.d. $6.5 \mathrm{~cm}$ ) containing $6 \mathrm{ml}$ of water. A tablet is kept on the paper nd the time for complete wetting is measured. The mean $\pm \mathrm{SD}$ values are calculated. ${ }^{54,19}$

\section{Water absorption ratio}

The weight of the tablet prior to placement in the petridish is noted $\left(\mathrm{w}_{\mathrm{b}}\right)$ utilizing a digital balance. The wetted tablet is removed and reweighed $\left(\mathrm{w}_{\mathrm{a}}\right)$. Water absorption ratio, $\mathrm{R}$ is then determined according to the following equation:

$\mathbf{R}=100 \times\left(\mathbf{w}_{\mathrm{a}}-\mathbf{w}_{\mathbf{b}}\right) / \mathbf{w}_{\mathbf{b}}$

Where, $w_{b}$ and $w_{a}$ are tablet weights before and after water absorption, respectively. The mean $\pm \mathrm{SD}$ values are calculated. ${ }^{49,55,56}$

\section{In vitro disintegration test}

Disintegration time is very important for MDTs which is desired to be less than 60 seconds for MDTs. This rapid disintegration assists swallowing of the tablet and also plays a role in drug absorption in buccal cavity, thus promoting bioavailability. In-vitro disintegration time is determined using disintegration test apparatus (Electrolab, USP model ED-2L) without disk for six tablets. The disintegration medium is $900 \mathrm{ml}$ of distilled water kept at $37 \pm 0.5^{\circ} \mathrm{C}$ and stirred at a rate of $30 \pm 2$ cycles $/ \mathrm{min}$. The time is measured in seconds for complete disintegration of the tablet with no palpable mass remaining in the apparatus. The test is carried out in triplicate. ${ }^{57,58}$

\section{Drug content uniformity}

This is determined by any standard assay method described for the particular API in any of the standard pharmacopoeia. Content uniformity is determined by estimating the API content in individual dosage form. ${ }^{1}$ Limit of content uniformity is $85-115 \%$.

\section{Swelling index}

The swelling index is the volume in milliliters occupied by 1 gram of a superdisintegrant, including any adhering superdisintegrant, after it is swollen in an aqueous liquid for $4 \mathrm{~h}$. In a $25 \mathrm{ml}$ ground-glass stoppered cylinder graduated over a height of $125 \pm 5 \mathrm{~mm}$ in $0.5 \mathrm{ml}$ divisions, $1.0 \mathrm{~g}$ of superdisintegrant is placed. Unless otherwise directed, the superdisintegrant is moistened with $1.0 \mathrm{ml}$ of alcohol, $25 \mathrm{ml}$ water is added and close the cylinder. The cylinder is shaken vigorously every $10 \mathrm{~min}$ for $1 \mathrm{~h}$. It is allowed to stand for $3 \mathrm{~h}$. At $90 \mathrm{~min}$ after the beginning of the test, any large volume of liquid retained in the layer of the superdisintegrant and any particle of superdisintegrant floating at the surface of liquid is released by rotating the cylinder about a vertical axis. The volume occupied by the superdisintegrant is measured, including any adhering mucilage. Three tests are carried out at the same time. The swelling index is calculated by the means of three tests. $^{16,59,60}$

\section{In-Vitro drug release studies}

The expansion of dissolution methods for MDTs is comparable to the approach taken for conventional tablets, and is practically indistinguishable. Media such as $0.1 \mathrm{~N}$ HCL and buffers ( $\mathrm{ph}-4.5$ and 6.8) should be evaluated for MDT much in the same way as their ordinary tablet counter parts. The USP 2 Paddle apparatus is used for this purpose which is the most suitable and common choice for MDTs, with a paddle speed of $50 \mathrm{rpm}$ commonly used. ${ }^{61}$ Typically the dissolution of MDT is very fast when using USP monograph conditions; hence slower paddle speeds may be utilized to attain a profile. The USP 1 Basket apparatus may have certain applications but sometimes tablet fragments or disintegrated tablet masses may become trapped on the inside top of the basket at the spindle where little or no effective stirring occurs, yielding irreproducible dissolution profiles.

\section{Moisture uptake studies}

This parameter should be conducted for MDTs to assess the stability of the dosage form. Ten tablets from each batch are kept in a desiccator over calcium chloride at $37^{\circ} \mathrm{C}$ for $24 \mathrm{~h}$. The tablets are weighed and exposed to $75 \%$ relative humidity, at room temperature for 2 weeks. Required humidity is attained by keeping saturated sodium chloride solution at the bottom of the desiccator for 3 days. One tablet as control (without superdisintegrants) is kept to check the moisture uptake by the other excipients. Tablets are weighed and the percentage increase in the weight is recorded. If the moisture uptake tendency of a weighed tablet is high, it requires special dehumidified area for manufacturing and packaging. ${ }^{44,62-65}$ The materials with high moisture resistant properties should be used for packaging for e.g. alu strip pack, alu-alu blister or polyethylene sealing on blister. The use of appropriate quantity of desiccant in High density polyethylene bottle packs with minimum head space is highly recommended to ensure stability of the product during its shelf life.

\section{IN-VIVO CHARACTERIZATION OF MDTS}

In-vivo studies exhibit the actual action of MDT in the oral-oesophageal tract, their pharmacokinetic and therapeutic efficacy, and acceptability. In-vivo test for the determination of disintegration time of MDTs can be conducted on volunteers who are usually randomized to receive the treatments and then directed to clean their mouth with water. Tablets are placed on their tongues, and the time for disintegration is measured by immediately starting a stopwatch. Immediately after the last noticeable granule has disintegrated, the stopwatch is stopped and the time recorded. ${ }^{66-68}$ In-vivo taste evaluation consists of a double blind crossover study, carried out on a trained panel of healthy volunteers with their prior assent. On keeping the dosage form in the oral cavity, the disintegration time is noted after which it is further held in mouth for $60 \mathrm{sec}$ by each volunteer, and the bitterness level is noted down against pure drug (control) using a numerical scale. The numerical scale bears the following value: $0=$ tasteless, 
$0.5=$ after taste, $1.0=$ slight, $1.5=$ slight to moderate, 2.0 $=$ moderate, $2.5=$ moderate to strong, $3=$ strong and $3+=$ very strong. A few examples are illustrated below, showing the work of various scientists in the field of invivo evaluation.

Panizo C et al., (2010) studied in-vivo immunological changes induced by a short course of grass Allergy Immunotherapy Tablets (AIT). They performed a randomized, double-blind placebo-controlled trial with 78 patients randomly assigned to receive either grass AIT or placebo in a 2:1 ratio and found that treatment with grass AIT for grass pollen allergic rhinoconjunctivitis induces immunological changes after only 1 month of treatment. ${ }^{69}$ Visser MR et al., (2010) adopted Inulin solid dispersion technology to improve the absorption of the BCS class IV drug TMC240. Single-dose study in dogs (200mg of TMC240), plasma concentrations of TMC240 remained below the lower limit of quantification $(<1.00 \mathrm{ng} / \mathrm{mL})$ in all animals ( $n=3$ per tested formulation), except in one dog receiving the inulin solid dispersion tablet $[\mathrm{C}$ (max) $=1.8 \mathrm{ng} / \mathrm{mL}$, AUC $(0-7 \mathrm{~h})=3.0 \mathrm{ngh} / \mathrm{mL}]$. The current data demonstrate that a solid dispersion of TMC240 in an inulin matrix allows considerable improvement in the release of poorly water-soluble TMC240, both in-vitro in the presence of a surfactant and in-vivo upon oral administration. ${ }^{70}$ Indumathi D et al., (2010) investigated in-vivo release studies of fluxetine fast dissolving tablet as control formulation and test formulation using rabbit as animal model. The plasma samples were separated by centrifugation and the drug was extracted. Then the samples were assayed by high performance liquid chromatography. ${ }^{71}$ They found that in-vivo drug release studies of test formulation were found to be better than that of control formulation. Gupta AK et al., (2011) carried out in-vivo mouth disintegration test for determination of disintegration time in saliva. They found that with increases in camphor ratio, tablet disintegrates rapidly in the saliva, which may be related to an improvement of the water penetration into the tablets due to high porosity. ${ }^{72}$

\section{CONCLUSION}

With the increase demand of novel drug delivery, the MDDDS has become one of the major mile stone of current investigations. This article attempts to present a detailed review regarding technological advances made so far in the area of evaluation of MDTs with respect to special characteristics of these inimitable dosage forms. Encouraging results of in-vivo evaluation revealed that in future, MDT may be most acceptable and prescribed dosage form due to its immediate action (within minute). Their characteristic advantages such as administration without water, anywhere, anytime lead to their increased patient compliance in today's scenario of hectic life.

\section{REFERENCES}

1. Sreeniwas SA, Dandagi PM, Gadad AP. Orodispersible tablets new fangled drug delivery system- a review. Ind. J. Pharm. Educ. Res. 2005; 39(4): 177-181

2. Siddiqui MN, Garg G, Sharma PK. A short review on "A novel approach in oral fast dissolving drug delivery system and their patents", Advances in Biological Research. 2011; 5(6): 291-303.

3. Konapure SA, Chaudhari PS, Oswal RJ, Kshirsagar SS, Antre RV, Chorage TV. Mouth dissolving tablets-an innovative technology, International Journal of Applied Biology and Pharmaceutical Technology. 2011; 2(1): 496-503.

4. Park JS, Shin KH, Park JB, Lee S, Hwang SJ. Disintegrating behavior of a rapidly disintegrating famotidine tablet formulation, J. Kor. Pharm. Sci. 2007; 37(5): 275-280.

5. Maya MT, Goncalves NJ, Silva NE, Filipe AE, Morais JA, Caturla MC, Rovira M. Comparitive bioavailability of two immediate release tablets of enalapril/hydrochlorothiazide in healthy volunteers, Eur. J. Drug Metab. Pharmacokinet. 2002; 27 91-99.

6. Lohitnavy M, Lohitnavy O, Wittaya-arrekul S, Sareekan K, Polnok S, Chaiyaput W. Average bioequivalence of clarithromycin immediate released tablet formulations in healthy male volunteers, Drug Dev. Ind. Pharm. 2003; 29: 653-659.

7. Carpay J, Schoenen J, Ahmad F, Kinrade F, Boswell D. Efficacy and tolerability of sumatriptan tablets in a fast-disintegrating, rapid-release formulation for the acute treatment of migraine: results of multicenter, randomized, placebo-controlled study, Clin. Ther. 2004; 26: 214-223.

8. Lindgren S, Janzon L. Dysphagia: prevalance of swallowing complaints and clinical finding, Med. Clin. North Am. 1993; 77: 3-5.

9. Sastry SV, Nyshadham JR, Fix JA. Recent technological advances in oral drug delivery: a review, Pharm. Sci. Technol. Today. 2000; 3: 138-145.

10. Fini A, Bergamante V, Ceschel GC, Ronchi C, De Moraes CAF. Fast dispersible/slow releasing ibuprofen tablets, Eur. J. Pharm. Biopharm. 2008; 69: 335-341.

11. Chang RK, Guo X, Burnside B, Couch R. Fast-dissolving tablets, Pharm. Technol. 2000; 24(6): 52-58.

12. Habib W, Khankari R, Hontz J. Fast-dissolving drug delivery system, Crit. Rev. Ther. Drug Carrier Syst. 2000; 17: 61-72.

13. Schettler T, Paris S, Pellett $M$, Kidner S, Wilkinson D. Comparative pharmacokinetics of two fast-dissolving oral ibuprofen formulations and a regular release ibuprofen tablet in healthy volunteers, Clin. Drug Invest. 2001; 21: 73-78.

14. Fu Y, Yang S, Jeong SH, Kimura S, Park K. Orally fast disintegrating tablets: developments, technologies, taste-masking and clinical studies, Crit. Rev. Ther. Drug Carrier Sys. 2004; 21(6): 433-475

15. Ghosh T, Ghosh A, Prasad D. A review on new generation orodispersible tablets and its future prospective, Int. J. Pharmacy and Pharm. Sci. 2011; 3(1): 1-7.

16. Chakraborty S, Khandari M, Singh Sp. Comparative study on effect of natural and synthetic superdisintegrants in the formulation of fast dissolving tablets, Int. J. Green Pharm. 2008: 22-25.

17. Bagul US. Current status of tablet disintegrants: a review, Pharma Info. Net, Available at: http://www.pharmainfo.net/reviews/current-status-tabletdisintegrants. Accesed on 180ct.2012.

18. Bhowmik D, Krishnakanth, Chiranjib B, Pankaj, Chandira RM. Fast dissolving tablet: an overview, J. Chem. Pharm. Res. 2009; 1(1): 163-177.

19. Hirani JJ, Rathod DA, Vadalia RK. Orally disintegrating tablets: a review, Tropical J. Pharm. Res. 2009, 8(2): 161-172.

20. Kaur T, Gill B, Kumar S, Gupta GD. Mouth dissolving tablets: a novel approach to drug delivery, Int. J. Curr. Pharm. Res. 2011; 3(1): 1-7.

21. Indurwade $\mathrm{NH}$, Rajyaguru TH, Nakhat PD. Novel approach: fast dissolving tablets, Indian Drugs. 2002; 39(8): 405-41.

22. Bradoo R. Fast dissolving drug delivery systems, JAMA India. 2001; 4(10): 27-31.

23. Jagani H, Patel R, Upadhyay P, Bhangale J, Kosalge S. Fast dissolving tablets: present and future prospectus, Journal of Advances in Pharmacy and HealthCare Research. 2011; 2(1): 57 70 .

24. Shaikh S, Khirsagar RV, Quazi A. Fast disintegrating tablets: an overview of formulation and technology, Int. J. Pharmacy and Pharm. Sci. 2010; 2(3): 9-15. 
25. Mudgal VK, Sethi P, Kheri R, Saraogi GK, Singhai AK. Orally disintegrating tablets: a review, Int. Res. J. Pharmacy. 2011; 2(4): $16-22$.

26. Chauhan VK, Umalkar DG, Singh LP, Shah K, Pagi K. Mouth dissolving tablets: an overview, J. Pharm. Biomed. Sci. 2011; 5(8): $1-6$.

27. Deshmukh KR, Patel V, Verma S, Pandey AK, Dewangan P. A review on mouth dissolving tablet techniques, Int. J. of Res. in Ayurveda and Pharmacy. 2011; 2(1): 66-74.

28. Parakh SR, Gothoskar AV. A review of mouth dissolving tablet technologies, Pharma Tech. 2003; 23: 92-100.

29. Biradar SS, Bhagawati ST. Fast dissolving drug delivery system: A brief overveiew, The Int. J. Pharmacol. 2006; 4(2): 15312972.

30. Slowson M, Slowson S. What to do when patients cannot swallow their medications", Pharm. Times. 1985; 51: 90-96.

31. Seager H. Drug-deliver products and the zydis fast-dissolving dosage form, J. Pharm. and Pharmacol. 1998; 50(4): 375-382.

32. Reddy LH, Ghose B, Rajneesh. Fast dissolviing drug delivery systems: a review of the literature, Indian J. Pharm. Sci. 2002; 64(4): 331-336.

33. Manivannan R. Oral disintegrating tablets: A future compaction, International Journal of Pharmaceutical Research and Development- Online. 2009; 1(10): 1-10.

34. Kulkarni SD, Pawar SP, Bakliwal SR, Rane BR, Gujrathi NA. Mouth dissolving tablet: an overview, Int. J. of Res. in Ayurveda and Pharmacy. 2011; 2(4): 1117-1123.

35. Bogner RH, Wilkosz MF. Fast dissolving tablets: new dosage convenience for patients, U.S. Pharm. 2002; 27: 34-43.

36. Kuchekar BS, Arumugam V. Fast dissolving tablets, Indian J. Pharm. Edu. 2001;35:150-152.

37. Bhaskaran S, Narmada GV. 'Orally disintegrating tablets', Indian Pharm acist. 2002; 1(2): 9-12.

38. Derajan PV, Gore SP. Express Pharma Pulse. 2000; 7(1): 23-16.

39. Patidar A, Mishra P, Main P, Harsoliya MS, Agrawal S. A review on- recent advancement in the development of rapid disintegrating tablet, International Journal of Life Science and Pharma Research. 2011; 1(1): 7-16.

40. Dobetti L. Fast disintegrating tablets, US Patent. 2003; 6: 596,311.

41. Brown D. Orally disintegrating tablets-taste over speed, Drug Del. Tech. 2003; 3(6): 58-61.

42. Kuchekar BS, Badhan AC, Mahajan HS. Mouth dissolving tablets: a novel drug delivery system, Pharma Times. 2003; 35: 7-9.

43. Wolany GJM, Munzer J, Rummelt A, Merkle HP. Buccal absorption of sandostatin (octreotide) in conscious beagle dogs, Proceed. Intern. Symp. Control. Rel. Bioact. Mater. 1990; 17: 224-225.

44. Siddiqui MN, Garg G, Sharma PK. Fast dissolving tablets: preparation, characterization and evaluation: an overview, Int. J Pharm. Sci. Rev. and Res. 2010; 4(2): 87-96.

45. Swamivelmanickam M, Manavalan R, Valliappan K. Mouth dissolving tablets: an overview, Int. J. Pharm. Sci. and Res. 2010; 1(12): 43-55.

46. Parikh DC, Amin AF. In vitro and In vivo techniques to assess the performance of gastro retantive drug delivery systems: a review, Expet. Opin. Drug Deliv. 2008; 5(9): 951-965.

47. Shukla D, Chakraborty S, Singh S, Mishra B. Mouth dissolving tablets II: an overview of evaluation techniques, Sci. Pharm. 2009; 77: 327-341.

48. Anand V, Kataria M, Kukkar V, Saharan V, Choudhury PK. The latest trends in the taste assessment of pharmaceuticals, Drug Discovery Today. 2007; 12: 257-265.

49. Battu SK, Repka MA, Rao AY. Formulation and evaluation of rapidly disintegrating fenoverine tablets: effect of superdisintegrants, Drug Dev. Ind. Pharm. 2007; 33: 1225-1232.

50. Desai SA, Kharade SV, Petkar KC. Orodissolving tablets of promethazine hydrochloride, Ind. J. Pharm. Educ. Res. 2006; 40(3): 172-174.

51. Lachman L, Liberman H, Kanig J. The theory and practice of industrial pharmacy, $3^{\text {rd }}$ edn., Varghese publishing house, Mumbai, 1987: 297.
52. Vora N, Rana V. Preparation and optimization of mouth/orally dissolving tablets using a combination of glycine, carboxymethyl cellulose and sodium alginate: a comparison with superdisintegrants, Pharm. Dev. Tech. 2008; 13(3): 233-243.

53. Khan S, Kataria P, Nakhat $P$, Yeole P. Taste masking of ondansetron hydrochloride by polymer carrier system and formulation of rapid-disintegrating tablets, AAPS Pharm. Sci. Tech. 2007; 8(2): 46.

54. Bi Y, Sunada H, Yonezawa Y, Danjo K. Preparation and evaluation of a compressed tablet rapidly disintegrating in the oral cavity, Chem. Pharm. Bull. 1996; 44: 2121-2127.

55. Mishra DN, Bindal M, Singh SK. Spray dried excipient base: A novel technique for the formulation of orally disintegrating tablets. Chem. Pharm. Bull. 2006; 54(1): 99-102.

56. Bi YX, Sunada H, Yonezawa Y, Danjo K. Evaluation of rapidly disintegrating tablets prepared by a direct compression method, Drug Dev. Ind. Pharm. 1999; 25: 571-581.

57. Alanazi FK. Evaluation of spray and freeze dried excipient bases containing disintegration accelerators for the formulation of metoclopramide orally disintegrating tablets, Saudi Pharm. J. 2007; 15(2): 105-119.

58. Jain CP, Naruka PS. Formulation and evaluation of fast dissolving tablets of valsartan, Int. J. Pharmacy and Pharm. Sci. 2009; 1(1): 219-226.

59. Indian Pharmacopoeia 1996, Government of India Ministry of healthy and family welfare, vol.1, Published by Controller of publications, Delhi. pp. 484-486.

60. British Pharmacopoeia 2005, vol.4. Published by the stationary office on behalf on the medicines and health care products regulatory agency. A250.

61. Wilson CG, Washington N, Peach J, Murray GR, Kennerley J. The behaviour of a fast dissolving dosage form (Expidet) followed by gammascintigraphy, Int. J. Pharm. 1987; 40(1-2): 119-123.

62. Allen T. In: Particle size measurement, $5^{\text {th }}$ ed. London: Chapmanand Hall, 1997: 149-187.

63. Alvarez-Lorenzo C, Go mez-Amoza JL, Marty nez-Pacheco R, Souto C, Concheiro A. Evaluation of low-substituted hydroxypropylcelluloses (L-HPCs) as filler binders for direct compression, Int. J. Pharm. 2000; 197: 107-116.

64. Sunada H, Bi Y. Preparation, evaluation and optimazation of rapidly disintegrating tablets, Powder Tech. 2002; 122: 188-198.

65. Koizumi KI, Watanabe Y, Morita K, Utoguchi N, Matsumoto M. New methods for preparing high porosity rapidly saliva soluble compressed tablets using mannitol with camphor, a subliming material, Int. J. Pharm. 1997; 152: 127-131.

66. Wilson CG, Washington N, Norman S, Greaves JL, Peach JM, Pugh K. A gamma scintigraphic study to compare oesophageal clearance of "Expidet" formulations, tablets and capsules in supine volunteers. Int. J. Pharm. 1988; 46(3): 241-246.

67. Dor PJM, Fix JA. In-Vitro determination of disintegration time of quick-dissolve tablets using a new method, Pharm. Dev. Technol. 2000; 5(4): 575-577.

68. Agarwal R, Mittal R, Singh A. Studies of ion-exchange resin complex of chloroquine phosphate, Drug Dev. Ind. Pharm. 2000; 26: 773-776.

69. Panizo C, Cimarra M, González ME, Vega A, Senent C, Martin S. In-Vivo and In-Vitro immunological changes induced by a short course of grass allergy immunotherapy tablets, J. Investig. Allergol. Clin. Immunol. 2010; 20(6): 454-462.

70. Visser MR, Baert L, Klooster G, Schueller L, Geldof M, Vanwelkenhuysen I, De Kock H, De Meyer S, Frijlink HW, Rosier J, Hinrichs WL. Inulin solid dispersion technology to improve the absorption of the BCS Class IV drug TMC240, Eur. J. Pharm. Biopharm. 2010; 74(2): 233-238.

71. Indhumathi D, Grace R. Design and optimization of orodissolving tablet of antidepressant drug by superdisintegrants addition method, Int. J. Pharm. Sci. Rev. and Res. 2010; 2(2): 19.

72. Gupta AK, Kumar A, Mishra DN, Singh SK. Formulation of rapid mouth dissolving tablets of cetrizine di $\mathrm{Hcl}$ using sublimation method, Int. J. Pharmacy and Pharm. Sci. 2011; 3(3):

285-287. 